\title{
Phosphorus/Sulfur Co-doped Porous Carbon with Enhanced Specific Capacitance for Supercapacitor and Improved Catalytic Activity for Oxygen Reduction Reaction
}

Yao Zhou ${ }^{1,2}$, Ruguang Ma ${ }^{1,2}$, Stephanie L. Candelaria ${ }^{3}$, Jiacheng Wang ${ }^{1,2, *}$, Qian Liu $^{1,2, *}$,Evan Uchaker ${ }^{3}$, Pengxi Li ${ }^{1}$, Yongfang Chen ${ }^{1,2}$, and Guozhong Cao ${ }^{3,4, *}$

1 The State Key Laboratory of High Performance Ceramics and Superfine Microstructure, Shanghai Institute of Ceramics, Chinese Academy of Sciences, 1295 Dingxi Road, Shanghai, 200050, China

${ }^{2}$ Shanghai Institute of Materials Genome, Shanghai, China

3 Department of Materials Science and Engineering, University of Washington, Seattle, WA 98195, USA

${ }^{4}$ Beijing Institute of Nanoenergy and Nanosystems, Chinese Academy of Sciences, Beijing 100083, China

* Author for correspondence. Email: jiacheng.wang@mail.sic.ac.cn;

qianliu@mail.sic.ac.cn; gzcao@u.washington.edu

Tel: 86-21-5241-2714, Fax: 86-21-5241-3122 


\section{Abstract}

Phosphorus (P) /sulfur (S) co-doped porous carbon derived from resorcinol and furaldehyde are synthesized through one-step sol-gel processing with the addition of phosphorus pentasulfide as $\mathrm{P}$ and $\mathrm{S}$ source followed with freeze-drying and pyrolysis in nitrogen. The $\mathrm{P} / \mathrm{S}$ co-doping strategy facilitates the pore size widening both in micropore and mesopore regions, together with the positive effect on the degree of graphitization of porous carbon through elimination of amorphous carbon through the formation and evaporation of carbon disulfide. As an electrode for supercapacitor application, $\mathrm{P} / \mathrm{S}$ co-doped porous carbon demonstrates $43.5 \%$ improvement on specific capacitance of the single electrode compared to pristine porous carbon in organic electrolyte at a current of $0.5 \mathrm{~mA}$ due to the P-induced pseudocapacitive reactions. As for electrocatalytic use, promoted electrocatalytic activity and high resistance to crossover effects of oxygen reduction reaction (ORR) in alkaline media are observed after the introduction of $\mathrm{P}$ and $\mathrm{S}$ into porous carbon. After air activation, the specific capacitance of the single electrode of sample PS-pC reaches up to $103.5 \mathrm{~F}$ $\mathrm{g}^{-1}$ and an improved oxygen reduction current density.

Key words: porous carbon; binary doping; supercapacitor; oxygen reduction reaction 


\section{Introduction}

The development of alternative and green energy sources has become an attractive research topic due to ever increasing global energy depletion and the environmental impact of traditional energy resources $[1,2]$. In electrochemical energy devices, such as fuel cells and capacitors, the designs of new materials at a low cost and keeping performance at a high level are key factors for commercialization. Heteroatom-doped (B, N, S, P et. al) porous carbon materials attracted significant attention because of their extensive application as a catalyst for the oxygen reduction reaction (ORR) in fuel cells [3-6] and in supercapacitors [7-9].

Doped porous carbons have great potential for use in supercapacitors due to their large gravimetric capacitance and electrical conductivity $[10,11]$. Numerous efforts have been devoted to S-doped carbon, a universal heterogeneous carbon-based electrode material. Usually, sulfur doping is preferential in polarizing electron pairs and improving degree of graphitization of carbon as well as introduction of redox reactions, due to its large size and high chemical activity [12-15]. The additional introduction of other heteroatom, such as $\mathrm{N}$, further alters the physical or chemical properties of carbon material and enhances its energy storage capability. Latest studies focused on binary-doped (S-N co-doping) carbon materials which performed better than single S-doped material. Zhang [16] synthesized S, N co-doped ordered mesoporous carbon (SNOMC) via a nanocasting strategy using oligomer of pyrrole as the precursor and sulfuric acid as the catalyst and sulfur source. The enhanced supercapacitive performance of NSOMC materials is mainly due to the improved 
surface activity and conductivity by incorporating nitrogen and sulfur into the carbon framework. Wang [17] adopted one-pot hydrothermal route using L-cysteine, an amino acid containing both $\mathrm{N}$ and $\mathrm{S}$, as the doping agent to successfully synthesize the $\mathrm{S}, \mathrm{N}$ co-doped graphene. The specific capacitance of co-doped sample showed a higher value than single-element doped sample. The coordinated effect of $\mathrm{S}$ and $\mathrm{N}$ was observed, which uplift the doping level of both elements, leading to increased capacitance and improved electrical conductivity.

As for ORR, S-doped porous carbons are also believed to be a promising metal-free electrocatalyst with high catalytic activity [18-20]. It is reported that sulfur-doping facilitates the enhanced spin or charge density in modified carbon $\pi$-system [21]. Compared to single S-doping, multiple-doping for ORR exhibits a superior catalytic performance. Qiao and co-workers [22] reported S and $\mathrm{N}$ dual-doped mesoporous graphene prepared by annealing graphene oxide with S- and $\mathrm{N}$-containing precursors; this showed excellent ORR performance comparable to that of commercial Pt/C catalysts. Xu [23] synthesized S, N dual-doping graphene oxide via chemical vapor deposition (CVD) method using pyrimidine and thiophene as precursors. The as-prepared dual-doped graphene oxide exhibited better catalytic activity than that of mono-doped carbon nanomaterials due to a synergetic effect of $\mathrm{N}$ and $\mathrm{S}$ co-doping. The controlling content and ratio of $\mathrm{S}$ and $\mathrm{N}$ also can be achieved by selecting pyrolysis temperature using a sole precursor (1-allyl-2-thiourea) [24]. The different concentration and ratio of incorporated $\mathrm{S}$ and $\mathrm{N}$ heavily affects the spin density, causing the variation of catalytic activity. 
Although co-doped (including sulfur) carbon materials potentially possess excellent properties for both supercapacitor and ORR, there are only a few reports about porous carbon that are simultaneously doped with sulfur and nitrogen [25]. Besides nitrogen, other substitutional heteroatom, such as $\mathrm{P}, \mathrm{B}, \mathrm{O}$, have also demonstrated to play a crucial role in modifying the electrical conductivity, surface activity and chemical reactivity, which are essential for supercapacitor and catalytic activity [26-28]. However, to our knowledge, besides S and N co-doped, other S, M ( $\mathrm{M}=\mathrm{P}, \mathrm{B}$ etc.) co-doped porous carbon for these two applications are not reported.

Phosphorus, one of the N-group elements, shows similar chemical properties to $\mathrm{N}$. It has been reported that $\mathrm{P}$ with larger atomic radius and higher electron-donating ability tends to induce more active sites for ORR and to improve electrocatalytic activity [29-31]. Additionally, $\mathrm{P}$ with lone pair of electrons can induce Faradaic reactions in addition to EDLC, indicating an increase in specific capacitance [32]. As a result, the co-doping of $\mathrm{P}$ and $\mathrm{S}$ to porous carbon may further explore the synergetic merits of $\mathrm{P}$ and $\mathrm{S}$, leading to enhanced electrocatalytic and pseudocapacitive properties. The study of S, P co-doping may bring a new insight and improvement on supercapacitor and catalytic performance for ORR.

The research performed here includes the synthesis of porous carbon by sol-gel processing with resorcinol and furaldehyde as precursors followed with controlled freeze drying and pyrolysis in nitrogen. Phosphorus pentasulfide $\left(\mathrm{P}_{2} \mathrm{~S}_{5}\right)$ acted as $\mathrm{P}$ and $\mathrm{S}$ source to one-step introduce $\mathrm{P}$ and $\mathrm{S}$. Air activated $\mathrm{P} / \mathrm{S}$ co-doped carbon was also synthesized to further increase the supercapacitive and catalytical properties. The non 
activated (PS-pC) and air activated (APS-pC) P/S co-doped porous carbon were used as electrodes for supercapacitors with an organic electrolyte consisting of $1 \mathrm{M}$ tetraethylammonium tetrafluoroborate (TEATFB) in 50-50 propylene carbonate-dmethylcarbonate (PC-DMC). In addition, the P/S co-doped porous carbon was utilized as the electrocatalysts for ORR in $0.1 \mathrm{M} \mathrm{KOH}$. The P/S co-doped carbon, as supercapacitive electrode material and metal-free catalysts, exhibited improved specific capacitance of the single electrode and favorable activity for ORR compared with pristine carbon. With air activation, sample APS-pC performed the excellent electrocatalytic activities for ORR and showed a value of single electrode specific capacitance of $103.5 \mathrm{~F} \mathrm{~g}^{-1}$.

\section{Experimental}

\subsection{Synthesis of P/S co-doped porous carbon (PS-pC and APS-pC) and pure porous carbon (pC)}

To prepare porous carbon, $1.26 \mathrm{~g}(0.01 \mathrm{~mol})$ resorcinol was dissolved in a solution containing $7.0 \mathrm{~g}$ of DI water, $7.0 \mathrm{~g}$ of ethanol under magnetic stirring until the solution turned transparent. Next, $0.06 \mathrm{~g}$ of hexamine was added as the catalyst and the solution was kept stirring for an additional $1 \mathrm{~h}$. Then, furaldehyde $(0.01 \mathrm{~mol})$ was added with another $1 \mathrm{~h}$ stirring. The mixture was sealed and cured in oven at $80{ }^{\circ} \mathrm{C}$ for 7 days to allow for gelation and aging to strengthen the newly formed three-dimensional gel network.

The resultant gel (RG) went through two different processes: for pure porous carbon, the gels were frozen and dried under vacuum at $-50{ }^{\circ} \mathrm{C}$ in a Labconco Free 
Zone 1L freeze dryer for three days; for P/S co-doped porous carbon, the gels were mixed with $0.01 \mathrm{~g}$ phosphorus pentasulfide $\left(\mathrm{P}_{2} \mathrm{~S}_{5}\right)$ in glove box filled with argon and then, transferred to the freeze dryer with the same drying parameters as synthesizing pure porous carbon. The dried samples were heated in $\mathrm{N}_{2}$ atmosphere at $1000{ }^{\circ} \mathrm{C}$ for 3 h. The obtained P/S co-doped porous carbon was denoted as PS-pC, while pure porous carbon was named as $\mathrm{pC}$.

To further uplift the performance, the as-prepared sample PS-pC was underwent post heat-treatment at $350{ }^{\circ} \mathrm{C}$ for $0.5 \mathrm{~h}$ in air for activation. The activated samples were denoted as APS-pC.

\subsection{Synthesis of P-doped porous carbon}

In order to obtain P-doped porous carbon for comparison, the as-prepared pure porous carbon $(\mathrm{pC})$ followed the same procedures described in section 2.1 was further undergone the treatment of phosphoric acid as described by Wu [33]. Typically, phosphoric acid was added to $\mathrm{pC}$ sample with a weight ratio of phosphoric acid: $\mathrm{pC}=$ 4:1. The mixture was kept at $85^{\circ} \mathrm{C}$ for $3 \mathrm{~h}$. The solvent in the mixture was removed in an evaporator operated at $85{ }^{\circ} \mathrm{C}$ and 300 mbar. Then, the as-prepared paste mixture was dried overnight in an oven at $85{ }^{\circ} \mathrm{C}$. The resultant powder was heat-treated under $\mathrm{N}_{2}$ atmosphere and kept at $500{ }^{\circ} \mathrm{C}$ for $1 \mathrm{~h}$. The prepared P-doped porous carbon was named as PpC.

\subsection{Synthesis of S-doped porous carbon}

The as-prepared $\mathrm{pC}$ sample mixed with sulfur flakes ( $\mathrm{pC}$ wt $\%$ : sulfur $\mathrm{wt} \%=10: 1$ ) and then the mixture was underwent the heat-treatment at $400{ }^{\circ} \mathrm{C}$ for $2 \mathrm{~h}$ in $\mathrm{N}_{2}$ 
atmosphere. The obtained sample was denoted as SpC.

\subsection{Synthesis of N/P/S porous carbon}

To further modified with nitrogen, the as-prepared PS-pC sample were further nitridation in $\mathrm{NH}_{3}$ atmosphere at $500{ }^{\circ} \mathrm{C}$ for $1 \mathrm{~h}$. The resultant porous carbon was denoted as NPS-pC.

\subsection{Characterization}

The atomic composition and surface functional groups of samples were determined by X-ray photoelectron spectroscopy (XPS). Spectra were taken on a Surface Science Instruments S-probe spectrometer. The X-ray spot size is $800 \times 800$ $\mu \mathrm{m}$ and the take-off angle is $55^{\circ}$, corresponding to a sampling depth of approximately 50-70 A. Data analyses was carried out using the Service Physics ESCA Hawk 7 Data Analysis Software (Service Physics, Bend, OR). The binding energy scales were calibrated assigning the lowest binding energy C1s peak a binding energy of $285.0 \mathrm{eV}$. Three spots were measured on each sample to make final results credible.

Pore parameters were obtained by analysis of nitrogen adsorption-desorption isotherms recorded on a Qutantachrome NOVA 4200e system. Samples were degassed at $100{ }^{\circ} \mathrm{C}$ under vacuum for at least $6 \mathrm{~h}$ prior to measurement. The total surface area was determined using the multipoint Brunauer-Emmett-Teller (BET) method. For the mesopore surface area, pore volume, and pore diameter, the Barrett-Joyner-Halenda (BJH) method was used. Micropore surface area and pore volume were determined using the t-method. Each sample was measured three times.

Surface morphologies of pores were observed by field emission scanning electron 
microscopy (FESEM, FEI Magellan 400, 5kV). Raman spectra were taken with an excitation wavelength of $532 \mathrm{~nm}$. Typically three spectra were taken for each sample to ensure uniformity. Thermal gravimetry-mass spectrometry (TG-MS) was applied to monitor the gas releasing during the pyrolysis.

\subsection{Electrochemical Analyses}

\subsubsection{Supercapacitive properties}

Electrodes were prepared by grinding the samples into a fine powder followed by mixing with $3.0 \mathrm{wt} \%$ PTFE as the binder. The resulting mixture was rolled into sheet with 60 um in the thickness. In order to make homogeneous thickness, the sheet during rolling was measured by the vernier caliper in different five areas several times until the whole sheet reached homogeneous thickness with $60 \mathrm{um}$. Then, the sheet was punched with a diameter of $10 \mathrm{~mm}$. A Celgard ${ }^{\circledR}$ porous film separates the electrodes and special carbon coated aluminum contacts were used to increase collector's conductivity and to prevent the aluminum from forming an oxide layer. The electrolyte used is $1 \mathrm{M}$ TEATFB in 50-50 PC-DMC. To test the electrodes, symmetrical two-electrode coin cells were assembled under an argon environment.

Cyclic voltammograms (CV) and galvanic cycle (GC) curves were measured by means of a Solartron 1287A with a voltage ranging between 0 and $2 \mathrm{~V}$. The CVs were measured at a scan rate of $10 \mathrm{mV} \mathrm{s}^{-1}$. Currents of $0.5 \mathrm{~mA}$ were applied in GC measurements. Electrochemical impedance analyses were carried out using the Solartron 1287A in conjunction with a Solartron 1260FRA/impedance analyzer. A frequency range between $0.1 \mathrm{MHz}$ and $1 \mathrm{MHz}$ and a $10 \mathrm{mV}$ AC voltage were used for 
this scan. The specific capacitance of the single electrode in Farad per gram $\left(\mathrm{F} \mathrm{g} \mathrm{g}^{-1}\right)$ was calculated from the discharge slope during galvanic cycles according to the following equation:

$$
\mathrm{C}_{\text {single-electrode }}=4 \mathrm{I} \Delta \mathrm{t} / \Delta \mathrm{Vm}
$$

Where $\mathrm{I}$ is the discharge current in amps, $\Delta \mathrm{t}$ is the discharge time in seconds, $\Delta \mathrm{V}$ is the discharge voltage in volts, and $\mathrm{m}$ is the mass of the active materials given in grams.

\subsubsection{Electrocatalytic activity for ORR}

The electrocatalytic experiment was performed in a standard three-electrode electrochemical cell, which was connected to an electrochemical workstation (WaveDriver20 Bipotentionstat/Galvanostat, Pine Research Instrumentation, USA) coupled with a rotating disk electrode (RDE) system (AFMSRCE3529, Pine Research Instrumentation, USA). A platinum sheet and a saturated calomel electrode (SCE) were used as the counter electrode and the reference electrode, respectively. To prepare the working electrode, $20 \mu \mathrm{L}$ of catalyst solution $\left(0.5 \mathrm{mg} \mathrm{mL}^{-1}\right)$ with $20 \mu \mathrm{L}$ Nafion was dropped onto the glassy carbon electrode (GCE, $0.19625 \mathrm{~cm}^{2}$ ) and dried at $50{ }^{\circ} \mathrm{C}$.

The CV measurements were performed in $\mathrm{O}_{2}$-saturated $0.1 \mathrm{M} \mathrm{KOH}$ solutions with a scan rate of $50 \mathrm{mV} \mathrm{s}^{-1}$. The $\mathrm{RDE}$ measurements were conducted in $\mathrm{O}_{2}$-saturated $0.1 \mathrm{M} \mathrm{KOH}$ solution at rotation speeds ranging from 400 to $2025 \mathrm{rpm}$ and with the scan rate of $10 \mathrm{mV} \mathrm{s}^{-1}$. The electron transfer numbers can be calculated from the slope and intercept of the Koutecky-Levich plots as follows: 


$$
\begin{aligned}
& 1 / \mathrm{J}=1 / \mathrm{J}_{\mathrm{k}}+1 /\left(\mathrm{B} \omega^{0.5}\right) \\
& \mathrm{B}=0.62 \mathrm{nF} v^{-1 / 6} \mathrm{C}_{0} \mathrm{D}_{0}^{2 / 3}
\end{aligned}
$$

Where $\mathbf{J}$ is the measured current density, $\mathrm{J}_{\mathrm{k}}$ is the kinetic current density, and $\omega$ is the revolution per minute of the disk. The constant 0.62 is adopted when the rotation speed is expressed in terms of rad; $n$ is the overall number of electrons transferred in oxygen reduction; $\mathrm{F}$ is the Faraday constant $\left(\mathrm{F}=96,485 \mathrm{C} \mathrm{mol}^{-1}\right), \mathrm{C}_{0}$ is the bulk concentration of oxygen $\left(\mathrm{C}_{0}=1.2 \times 10^{-3} \mathrm{~mol} \mathrm{~L}^{-1}\right), v$ is the kinematic viscosity of the electrolyte $\left(v=0.1 \mathrm{~m}^{2} / \mathrm{s}\right.$ in $\left.0.1 \mathrm{M} \mathrm{KOH}\right)$ and $\mathrm{D}_{0}$ is the diffusion coefficient of oxygen in $0.1 \mathrm{M} \mathrm{KOH}\left(\mathrm{D}_{0}=1.9 \times 10^{-5} \mathrm{~cm} \mathrm{~s}^{-1}\right)$.

\section{Results and Discussion}

\subsection{Composition and pore structure}

The high-resolution XPS spectra of C1s, P2p and S2p for sample PS-pC were measured to analyze the chemical environment of the S-, P-doped carbon structures (Figure 1). The compositional data from XPS is presented in Table 1. For C 1s, the sample was deconvoluted into six bands: a main peak at $284.6 \mathrm{eV}$ assigned to the graphitic structure C-C sp ${ }^{2}$ [34]; a peak at $285.4 \mathrm{eV}$ attributed to carbon-carbon single bonds of defects $\left(\mathrm{C}-\mathrm{C} \mathrm{sp}{ }^{3}\right)$ or carbon-phosphorus single bond (C-P) on the carbon matrix [35]; a peak at $286.5 \mathrm{eV}$ related to carbon-oxygen-phosphorus single bonds (C-O-P) [35]; a peak at 287.1 eV due to carbon-oxygen double bonds $(\mathrm{C}=\mathrm{O})$ [34]; a peak at $288.4 \mathrm{eV}$ assigned to carbon-oxygen double bonds $(\mathrm{O}-\mathrm{C}=\mathrm{O})$ [34]; and a peak at $291.4 \mathrm{eV}$ attributed to the $\pi-\pi^{*}$ shake-up satellite peak from the $\mathrm{sp}^{2}$-hybridized carbon atoms [34]. The specific carbon-sulfur bonding information in C 1s spectra 
could not be discriminated due to the contribution of C-C bonds overwhelming the bonding information between carbon and sulfur.

The XPS spectra for P2p in the sample PS-C exhibited two featured peaks at $132.8 \mathrm{eV}$ and $133.9 \mathrm{eV}$ which are attributed to $\mathrm{P}-\mathrm{C}$ and $\mathrm{P}-\mathrm{O}$ bonding, respectively [35]. The presence of P-C bonds confirms that $\mathrm{P}$ was successfully doped in sample PS-pC. Additionally, the high resolution spectrum for S2p was fitted to three bands. Two peaks at $164.2 \mathrm{eV}\left(\mathrm{S} 2 \mathrm{p}_{3 / 2}\right)$ and $165.4 \mathrm{eV}\left(\mathrm{S} 2 \mathrm{p}_{1 / 2}\right)$ were constrained by a 2:1 concentration ratio and $1.2 \mathrm{eV}$ binding energy separation, corresponding to spin-orbital splitting of thiophene-like $\mathrm{S}$ incorporated into the graphite structure; another peak at $168.6 \mathrm{eV}$ was ascribed to the existence of sulfone bonds [36]. It should be noted that the content of $\mathrm{P}(1.3$ at $\%)$ in the carbon matrix are over two times than that of $\mathrm{S}(0.4 \mathrm{at} \%)$ in the sample. According to stoichiometric proportion of $\mathrm{P}_{2} \mathrm{~S}_{5}$, more $\mathrm{S}$ should embed in the carbon matrix instead of $\mathrm{P}$. It is supposed that when $\mathrm{P}_{2} \mathrm{~S}_{5}$ reacts with carbon in inert atmosphere, $\mathrm{S}$ tends to be more readily eliminated as gaseous $\left(\mathrm{CS}_{2}, \mathrm{H}_{2} \mathrm{~S}\right.$ et al), while $\mathrm{P}$ is stable in carbon matrix. In order to verify this assumption, the carbon gel mixed with $\mathrm{P}_{2} \mathrm{~S}_{5}$ before pyrolysis underwent heat treatment up to $1000{ }^{\circ} \mathrm{C}$ to get the mass spectrum for released gases under nitrogen in Figure 2. S-containing gas $\left(\mathrm{CS}_{2}\right)$ was released while only trace amount of $\mathrm{P}_{4}$ gas (only a broad peak) was detected. Compared to the release amount of $\mathrm{CS}_{2}$, the loss of $\mathrm{P}_{4}$ can be ignored. This result supports the assumption above that $S$ is more readily removed from carbon matrix with heat-treatment than $\mathrm{P}$.

Table 1 XPS composition data for samples PS-pC and pC. 


\begin{tabular}{lllll}
\hline Sample & S & P & O & C \\
ID & Atomic \% & & & \\
\hline PS-pC & 0.4 & 1.3 & 8.5 & 89.8 \\
pC & - & - & 8.7 & 91.3 \\
\hline
\end{tabular}

The SEM images (Figure S1) suggests that samples PS-pC and $\mathrm{pC}$ are porous with piling up pores and irregular morphology. To further demonstrate their porous structures, nitrogen sorption was used to determine the surface area, pore volume, and pore size distribution. Nitrogen sorption isotherms, mesopore size distributions and micropore size distributions are shown in Figure $3 \mathrm{a}, \mathrm{b}$ and $\mathrm{c}$. The corresponding data from nitrogen sorption measurements are presented in Table 2. Samples exhibited type IV isotherms with a nearly H4 type hysteresis loop [37]. It is believed that the H4 is associated with the existence of narrow silt-like pores, caused by the particle piling up. The results of nitrogen sorption are well consistent with the observation from SEM images. Notably, the pristine porous carbon contains a considerable amount of micropores, leading to diverged hysteresis at low relative pressure [38]. In contrast, the sample PS-pC shows a well closed loop, indicating co-doping decreased amount of micropores in carbon matrix.

Figure $3 \mathrm{~b}$ and $\mathrm{c}$ show the pore size distribution curves of the sample PS-pC and pC calculated by using the $\mathrm{BJH}$ model and DA method, respectively. A distribution peak at $5.0 \mathrm{~nm}$ in PS-pC which was not in $\mathrm{pC}$, presents the trend of pore widening effect of co-doping. The manifested peak at $8.2 \mathrm{~nm}$ in sample $\mathrm{pC}$ disappeared and emerged to a larger pore size in sample PS-pC, further supporting the pore size widening. In addition, the maximum distribution of micropores was changed from 1.5 
$\mathrm{nm}$ to $1.8 \mathrm{~nm}$, which also confirms that the introduction of P- and S-heteroatoms is benevolent to enlarge pore size (Figure 3c). Furthermore, the P, S co-doping into carbon matrix resulted in an increase in the mesopore volume (Table 2). The BET specific surface area for porous carbon decreased from 313.7 to $268 \mathrm{~m}^{2} \mathrm{~g}^{-1}$ after $\mathrm{P}, \mathrm{S}$ co-doping, which demonstrates the different trend in the region of mesopore and micropore. After co-doping of $\mathrm{P}$ and $\mathrm{S}$, the mesopore surface increased from 117.9 to $143.7 \mathrm{~m}^{2} \mathrm{~g}^{-1}$, while the micropore surface decreased from 201.3 to $145.8 \mathrm{~m}^{2} \mathrm{~g}^{-1}$, possibly resulting from pore widening.

Table 2 Nitrogen sorption data for samples PS-pC and pC.

\begin{tabular}{ccccccc}
\hline $\begin{array}{c}\text { Sample } \\
\text { ID }\end{array}$ & $\begin{array}{c}\mathrm{S}_{\mathrm{BET}} \\
\mathrm{m}^{2} \mathrm{~g}^{-1}\end{array}$ & $\mathrm{~S}_{\text {Meso }}$ & $\mathrm{S}_{\text {Micro }}$ & $\begin{array}{c}\mathrm{V}_{\text {Meso }} \\
\mathrm{cm}^{3} \mathrm{~g}^{-1}\end{array}$ & $\mathrm{~V}_{\text {Micro }}$ & $\begin{array}{c}\text { D Meso } \\
\mathrm{nm}\end{array}$ \\
\hline PS-pC & 268.0 & 143.7 & 145.8 & 0.48 & 0.01 & 5.5 \\
pC & 313.7 & 117.9 & 201.3 & 0.40 & 0.05 & 4.2 \\
\hline
\end{tabular}

\subsection{Degree of graphitization}

It has been reported that $\mathrm{S}$-doped carbon has an improved degree of graphitization due to the imperfect carbon atoms in carbon matrix can be efficiently removed by the S-containing gases [15]. To investigate the effect of P/S co-doping on the degree of graphitization for carbon, Raman spectroscopy was adopted. To determine the degree of graphitization, the peak intensity ratios of the $D$ and $G$ bands, denoted as $I(D) / I(G)$, were compared between sample PS-pC and pC (Figure 4). A higher value of I(D)/I(G) indicates a lower degree of graphitization. Due to the overlap of the D and G bands, peak fitting was performed following the procedure outlined by Vallerot [39]. All 
samples exhibit the characteristic features of graphitic materials, with D and G bands at $\sim 1339 \mathrm{~cm}^{-1}$ and $\sim 1589 \mathrm{~cm}^{-1}$, respectively. The D band stems from a double resonance process involving a phonon and a defect. The $\mathrm{G}$ band corresponds to in-plane vibrations and has $\mathrm{E}_{2 \mathrm{~g}}$ symmetry. The fitted spectra of sample PS-C and PC and their corresponding values of $\mathrm{I}(\mathrm{D}) / \mathrm{I}(\mathrm{G})$ are shown in Figure 4. Additional bands are labeled as I and D". The I band is linked with disorder in the graphitic lattice, $\mathrm{sp}^{2}-\mathrm{sp}^{3}$ bonds or the presence of polyenes and is seen at $\sim 1180-1290 \mathrm{~cm}^{-1}[40,41]$. The D" band $\left(\sim 1500 \mathrm{~cm}^{-1}\right)$ is known to occur in the presence of amorphous carbon [42]. The spectra shows that the value of $\mathrm{I}(\mathrm{D}) / \mathrm{I}(\mathrm{G})$ decreases from 0.99 to 0.80 after P- and S-doping, indicating the enhanced degree of graphitization. The high degree of graphitization demonstrates the improved integrity of carbon with few defects. In the previous work, $\mathrm{S}$ has proven to react with imperfect carbon in carbon matrix to form $\mathrm{CS}_{2}$ gas [14]. The elimination of $\mathrm{CS}_{2}$ gas facilitates the removal of imperfect carbon, and then leads to higher degree of graphitization [14]. Unlike $\mathrm{S}$ doping, $\mathrm{P}$ incorporated in carbon hardly reacts with imperfect carbon to form P-carbon containing gases (Figure 2), suggesting no supplementary effect of $\mathrm{P}$ on the degree of graphitization. As a result, the increased degree of graphitization of sample PS-pC should be ascribed to the S-induced graphitization process. The improved degree of graphitization may result in the drop of resistance and increase in conductivity, followed by the improvement of supercapacitive and catalytic performances.

\subsection{Supercapacitive Performance}

$\mathrm{CV}$ measurements with a scan rate of $10 \mathrm{mV} \mathrm{s}^{-1}$ are shown in Figure 5a. The 
nearly rectangular shape of CV curves of samples PS-pC and $\mathrm{pC}$ indicates capacitive behavior from the formation of electric double layers. Sample PS-pC exhibited redox reaction peaks in the potential range from 0.8 to $1.5 \mathrm{~V}$ in addition to the rectangular shape, which suggests the existence of pseudocapacitive reactions. However, the redox peaks were difficult to discern in the sample $\mathrm{pC}$, implying no detectable pseudocapacitance existed in this sample. The oxygen content of sample pC was 8.7 at\%, which was only 0.2 at $\%$ higher than that of sample PS-pC. The 0.2 at $\%$ in difference can be ascribed to the issue of XPS equipment accuracy. In addition, if redox reactions introduced by oxygen, sample $\mathrm{pC}$ with higher oxygen content of 8.7 at\% should exhibit the redox peaks instead of sample PS-pC. However, no broad peak was found in sample $\mathrm{pC}$, indicating oxygen did not induce pueudocapacitance. It also should be noted that $\mathrm{S}$ content in sample PS-pC is 0.4 at $\%$. In the former study, redox peaks can be found in CV curves when sulfur content is equal or greater than 1.4 at $\%$ (Table S1). Below this value of content, the redox reactions cannot be detected. It means the redox peaks in sample PS-pC is not caused by $\mathrm{S}$ because $\mathrm{S}$ content in sample PS-pC (0.4 at $\%)$ is far from 1.4 at $\%$. There is no other element in the samples that can cause faradaic reactions except oxygen, $\mathrm{S}$ and $\mathrm{P}$, so the pseudocapacitance can only be introduced by P in sample PS-pC.

The exact mechanism for P inducing pseudocapacitance in sample PS-pC is still unknown at this time. However, following the reactions discussed earlier for nitrogenated carbon in organic medium [43], new reactions can be proposed for PS-pC in organic electrolytes. It is believed that pseudocapacitance arises from 
Faradaic reactions induced by lone electron pairs from the $\mathrm{P}$ groups interacting with the cations in the electrolyte. The following reactions could take place on the PS-pC sample:

$$
\begin{gathered}
-\mathrm{C}-\mathrm{PH}_{2}:+\left(\mathrm{C}_{2} \mathrm{H}_{5}\right)_{4}{ }^{+} \leftrightarrow-\mathrm{C}-\mathrm{PH}_{2}:\left(\mathrm{C}_{2} \mathrm{H}_{5}\right)_{4}{ }^{+} \\
-\mathrm{C}=\mathrm{PH}:+\left(\mathrm{C}_{2} \mathrm{H}_{5}\right)_{4}^{+} \leftrightarrow-\mathrm{C}=\mathrm{PH}:\left(\mathrm{C}_{2} \mathrm{H}_{5}\right)_{4}^{+} \\
-\mathrm{C} \equiv \mathrm{P}:+\left(\mathrm{C}_{2} \mathrm{H}_{5}\right)_{4}^{+} \leftrightarrow-\mathrm{C} \equiv \mathrm{P}:\left(\mathrm{C}_{2} \mathrm{H}_{5}\right)_{4}^{+}
\end{gathered}
$$

Figure $5 b$ shows the Galvanic cycling curves (GCs) measured at a current of 0.5 $\mathrm{mA}$. Notably, the discharge time of the PS-pC sample is higher than that of the $\mathrm{pC}$ sample. Furthermore, it is found that sample PS-pC presented a smaller potential drop (IR drop) compared to sample $\mathrm{pC}$, indicating that the PS-pC electrode has a better conductivity and smaller resistance. This result matches well with the former assumption that S-induced graphitization process facilitates the improvement of conductivity.

The specific capacitance of the single electrode was calculated from the discharge slopes of these curves using eqn (1). The results are shown in Table 3. Sample PS-pC had the most gradual discharge slope (Figure 5b), resulting in the higher specific capacitance. The specific capacitance of the single electrode is $21.1 \mathrm{~F} \mathrm{~g}^{-1}$, which is 43.5\% higher than that of the unmodified carbon sample $\left(14.7 \mathrm{~F} \mathrm{~g}^{-1}\right)$. It should be noted that the content of sulfur is only 0.4 at $\%$ in sample PS-pC, which is below the minimum content $(1.4$ at $\%)$ of redox peaks occurrence. Even though sulfur rarely contributes to pseudocapacitance, it did facilitate the graphitization of porous carbon by reaction and removal of incomplete carbon atom to form gaseous carbon disulfide. 
The sulfur-induced graphitization reduced the resistance of porous carbon and led to enhanced conductivity, which was supported by impedence analysis with decreased radius of semicircle. The decreased resistance helps to reduce the electron loss during the transportation. On the other hand, phosphorus as defects was introduced to carbon, leading to jeopardized degree of graphitization of porous carbon. However, phosphorus caused reversible Faradaic reactions in organic electrolyte, supplying the additional capacitance.

It is important that these samples have in no way been optimized to achieve high capacitance values. The present goal is to investigate if $\mathrm{P} / \mathrm{S}$ doping can improve capacitance. According to nitrogen sorption, the total surface areas of both samples are relatively small, as some studies on activated carbon have achieved surface areas exceeding $2000 \mathrm{~m}^{2} \mathrm{~g}^{-1}$ [44]. As such, Table 3 also shows the capacitance of sample PS-pC normalized to surface area to minimize effects of specific surface area. The value of sample PS-pC is $\mathrm{C}_{\text {surface-area }}=0.08 \mathrm{~F} \mathrm{~m}^{-2}$. Compared to the S-doped porous carbon (sulfur was introduced from a S-containing precursor named as 2-thiophenecarboxaldehyde) in organic electrolyte in former study, the P/S co-doped carbon prepared in this work improves in specific capacitance based on total surface area. At a current of $0.5 \mathrm{~mA}$, sample PS-pC showed a value of $0.08 \mathrm{~F} \mathrm{~m}^{-2}$ in specific capacitance based on total surface area, which is twice of that of sulfur-doped porous carbon $\left(\mathrm{C}_{\text {surface-area }}=0.04 \mathrm{~F} \mathrm{~m}^{-2}\right)$ with sulfur content of 1.4 at $\%$ [14]. It should be noted that the specific capacitance of sulfur-doped carbon is $738.5 \mathrm{~m}^{2} \mathrm{~g}^{-1}$, which is 2.8 times of that of sample PS-pC. As a result, the reason for improved $\mathrm{C}_{\text {surface-area }}$ is ascribed to 
the introduction of phosphorus instead of optimized pore structure. Based on the comparisons mentioned above, the advantage of $\mathrm{P} / \mathrm{S}$ co-doping in improving the value of $\mathrm{C}_{\text {surface-area }}$ has been clearly observed, showing the enhanced charge storage capability on the unit surface area of P/S co-doping.

Table 3 Specific capacitance of the single electrode of sample pC and PS-pC.

\begin{tabular}{ccc}
\hline Sample ID & $\begin{array}{c}\mathrm{C}_{\text {single-electrode }} \\
\left(\mathrm{F} \mathrm{g}^{-1}\right)\end{array}$ & $\begin{array}{c}\text { Capacitance based on total } \\
\text { surface area } \mathrm{C}_{\text {surface-area }}\left(\mathrm{F} \mathrm{m}^{-2}\right)\end{array}$ \\
\hline pC & 14.7 & 0.05 \\
PS-pC & 21.1 & 0.08 \\
\hline
\end{tabular}

The electrochemical stability of sample PS-pC and $\mathrm{pC}$ is shown in Figure 6a. After 2000 cycles of charge and discharge, both materials did not show evident loss of capacitance (less than 6\%), and sample PS-pC with $98.6 \%$ capacitance retention showed even better durability than sample pC. The good electrochemical stability of PS-pC can be ascribed to two parts: first, relative larger mesopore size and volume than that of $\mathrm{pC}$, enhance the organic electrolyte's mobility inside mesopores which prevents "trapped mesopores" from electrolyte filling in small size pores which are hard to be moved out; second, incorporated sulfur in PS-pC enhanced the conductivity of the carbon matrix, which guarantees the amount retention of electrons during transportation.

Electrochemical impedance spectroscopy (EIS) provides insight into how P/S co-doping affecting the performance of the sample. The Nyquist plots of samples PS-pC and pC are shown in Figure 6b. The impedance plots of both samples showed almost similar profiles with one semicircle at the high frequency region followed by a linear part in the low frequency region. It is known that a slope of the linear part at 
low frequency close to $90^{\circ}$ along the imaginary axis Z" is a characteristic of ideally polarizable electrode, while the high frequency large semicircle is indicative of the high interfacial charge-transfer resistance due to the poor electrical conductivity of electrode materials [45]. As seen in Figure 6b, the sample PS-pC had a smaller semicircle compared to $\mathrm{pC}$, implying a good capacitive performance and lower interfacial charge-transfer resistance in the PS-pC sample. This result has a good agreement with GC curves in which IR dropped after P/S co-doping.

In addition, sample PS-pC not only shows a better charge storage capability than pristine sample $\mathrm{pC}$, but also surpasses that of single P-doped $(\mathrm{PpC})$ and S-doped (SpC). Compared with the specific surface area of PS-pC $\left(268.0 \mathrm{~m}^{2} / \mathrm{g}\right)$, sample SpC exhibits a larger value of $\mathrm{S}_{\mathrm{BET}}\left(289.5 \mathrm{~m}^{2} / \mathrm{g}\right.$, Table $\left.\mathrm{S} 2\right)$. However, the specific capacitance of SpC (Figure S2 and Table S3) is lower than that of sample PS-pC. It should be noted that the sulfur content of sample $\mathrm{SpC}(0.5$ at $\%$, Table S4) is comparable to that of PS-pC (0.4 at\%) and sulfur chemical status (Figure S3) are also similar to that of PS-pC. Thus, the deteriorated specific capacitance of sample SpC is due to the absence of phosphorus. The similar result is also observed in sample PpC (except specific surface area is comparable to that of PS-pC) that specific capacitance of single P-doped sample (PpC) lower than that of PS-pC. These results illustrate that P/S co-doping performs superior charge storage capability than that of single doping. Furthermore, nitrogen-doping are considered as an efficient method to improve the supercapacitive performance of porous carbon by introduction of pseudocapacitance [16]. In order to investigate the effect of nitrogen absence, N/P/S triple-doped porous 
carbon (NPS-pC) was synthesized to compare with sample PS-pC. With comparable S, P content (Table S4) and specific surface area $\left(247.7 \mathrm{~m}^{2} / \mathrm{g}\right)$, the specific capacitance of NPS-pC (21.5 F/g, Figure S2 and Table S3) shows a mild increase (1.8\%) when compared to that of PS-pC $(21.1 \mathrm{~F} / \mathrm{g})$. This increase in specific capacitance of NPS-pC is ascribed to the contributions of nitrogen. However, the introduction of nitrogen should have affected more significantly [46] instead of only $1.8 \%$ improvement. This indicates that there is another strategy to synergistically influence the performance. It should be noted that the introduction of nitrogen increases the value of $\mathrm{I}(\mathrm{D}) / \mathrm{I}(\mathrm{G})$ from 0.8 (PS-pC) to 1.02 (NPS-pC) as shown in Figure S4, which illustrates a decreased degree of graphitization. It is believed that high degree of graphitization is beneficial to improve the specific capacitance [47]. Interestingly, $\mathrm{P}$ and $\mathrm{S}$ as dopants into pristine porous carbon improved the degree of graphitization while further introduction of $\mathrm{N}$ has the opposite effect. As mentioned in Part 3.2, existence of $\mathrm{S}$ has proven to react with imperfect carbon in carbon matrix to form $\mathrm{CS}_{2}$ gas and the elimination of $\mathrm{CS}_{2}$ gas facilitates the removal of imperfect carbon, leading to higher degree of graphitization [14]. The elimination of $\mathrm{CS}_{2}$ can overwhelm the negative effect of $\mathrm{P}$ heteroatom on degree of graphitization. However, only 1 at $\%$ loss of sulfur when compare NPS-pC (0.3 at $\%)$ with PS-pC (0.4 at $\%)$, indicating nearly no release of sulfur-containing gas to offset the effect of $\mathrm{N}$ on degree of graphitization. As a result, the increase of specific capacitance derived from redox reactions of $\mathrm{N}$-doping is partially counteracted by decreased degree of graphitization, causing not apparent improvement in specific capacitance. 
When sample PS-pC were activated in air at $350{ }^{\circ} \mathrm{C}$ for $0.5 \mathrm{~h}$, both surface area and pore volume increased appreciably (Table 4). Consequently, the specific capacitance of sample APS-pC reached 103.5 F g-1 (Figure 6c), showing that such a P, $\mathrm{S}$ co-doped porous carbon has much potential to improve performance and is suitable for use as supercapacitors.

\subsection{Electrocatalytic activity for ORR}

The CV and RDE curves were performed to measure the catalytic activities of PS-pC and pC samples for cathodic ORR. First, the ORR activity of both samples was examined by $\mathrm{CV}$ in $\mathrm{N}_{2}$-saturated and $\mathrm{O}_{2}$-saturated $0.1 \mathrm{M} \mathrm{KOH}$ solutions. In Figure 7a, the obvious reduction peaks occurred in the $\mathrm{O}_{2}$-saturated $0.1 \mathrm{M} \mathrm{KOH}$ solution using PS-pC and pC as catalysts, while the featureless peaks were observed within the same potential range in the $\mathrm{N}_{2}$-saturated $0.1 \mathrm{M} \mathrm{KOH}$ solution. The ORR peak potential is $-0.36 \mathrm{~V}$ for sample PS-pC, which is $0.03 \mathrm{~V}$ more positive than that of sample pC. For the PS-pC and $\mathrm{pC}$, the onset potentials are $-0.12 \mathrm{~V}$ and $-0.17 \mathrm{~V}$, respectively (Figure 7b). In addition, the current density of sample PS-pC demonstrated a higher value than that of pC. It should be noted that the increased mesopore size and mesopore surface area are believed to facilitate the $\mathrm{O}_{2}$ diffusion [48]. Remarkably, the PS-pC electrode exhibited more positive onset potential and larger current density than $\mathrm{pC}$ electrode. Clearly, the positive shift of onset potential and enhancement of reduction current on PS-pC electrode indicate that sample PS-pC possesses much higher electrocatalytic activity toward ORR than pC. RDE measurements of sample PS-pC (Figure 7c) and $\mathrm{pC}$ (Figure 7d) were performed with varying rotation speeds from 400 
to $2025 \mathrm{rpm}$. The oxygen reduction current density gradually increased with speeding-up rotation rate. The Koutecky-Levich plots at different electrode potentials derived from Figure $7 \mathrm{c}$ displayed good linearity (Figure $7 \mathrm{c}$ inset). The PS-pC electrode has the larger transferred electron numbers of 2.8-3.1 within the potential range of -0.67 to $-0.37 \mathrm{~V}$ than pure $\mathrm{pC}$, signifying that an oxygen reduction reaction is more close to four-electron ORR pathway after P/S co-doping. It is believed that the four-electron pathway is the most efficient because oxygen could be directly reduced to $\mathrm{OH}^{-}$without the intermediate product $\left(\mathrm{H}_{2} \mathrm{O}_{2}\right)$ [49]. As a result, $\mathrm{P} / \mathrm{S}$ co-doping facilitates the improvement on the peak potential, electron transfer number, onset potential and current density, leading to an enhanced catalytic activity compared to un-modified sample pC.

As for the role of sulfur in catalytic application, it has been proved that sulfur facilitated the degree of graphitization. Increased degree of graphitization will surely improve the electrical conductivity of porous carbon, which is beneficial to enhance the ORR activity [50]. In addition, sulfur affects the catalytic activity by the mismatch of the outermost orbital of sulfur and carbon [22]; then, sulfur is positively charged and can be viewed as the catalytic center for ORR [21]. As for phosphorus, a larger atomic radius and higher electron-donating ability, tends to induce more active sites for ORR and to improve electrocatalytic activity [29-31]. It is believed that $\mathrm{S}$ and $\mathrm{N}$ dual-doping uplifted the maximum spin density compared to single-element doping, indicating elevated ORR activity. Phosphorus, one of the N-group elements, shows similar chemical properties to $\mathrm{N}$. As a result, the synergistic effects of S, N co-doping 
in elevating maximum spin density to increase ORR activity may also be suitable for S, P co-doping. It also can be observed that sample PS-pC exhibits more positive onset potential $(-0.12 \mathrm{~V})$ and larger current density than those of single doped samples PpC and SpC (Figure S5). Furthermore, degree of graphitization of sample NPS-pC decreased after nitrogen introduction into sample PS-pC (Figure S4). Even though nitrogen-doping is reported to increase ORR activity due to inducing positively charged carbon atoms [51], the onset potential and current density of NPS-pC (Figure S5) is comparable to those of PS-pC. It is due to the deteriorated degree of graphitization of NPS-pC caused by the insufficient release of $\mathrm{CS}_{2}$ to remove imperfect carbon atoms. The decreased degree of graphitization would decrease the catalytic activity [50] and offsets the positive effects of N-doping on ORR reaction as shown in Figure S5.

In addition, electrocatalytic selectivity of sample PS-pC and $20 \% \mathrm{Pt} / \mathrm{C}$ against the electrooxidation of methanol were measured to examine possible crossover effects in an $\mathrm{O}_{2}$-saturated $0.1 \mathrm{M} \mathrm{KOH}$ solution by adding $6 \mathrm{~mL}$ of methanol at $300 \mathrm{~s}$. The ORR current of commercial $\mathrm{Pt} / \mathrm{C}$ catalyst exhibited a sudden change after the methanol injection due to the electrochemical oxidization of methanol (Figure 8a). In comparison, sample PS-pC remained almost unchanged under the same condition. As a result, sample PS-pC exhibited high selectivity toward ORR with excellent performance in avoiding crossover effects, which had an advantage over the $\mathrm{Pt} / \mathrm{C}$ catalyst.

It is believed that optimization of the pore structure of catalyst is an efficient way 
to further improve catalytic properties. As a result, air activation was introduced to improve the pore structure of sample PS-pC. The activated PS-pC sample was denoted as APS-pC. As shown in Table 4, the surface area, pore volume and pore size of APS-pC were increased significantly compared to those of sample PS-pC, which may facilitate the oxygen diffusion and increased oxygen reduction current density. It can be also supported by RDE measurements of APS-pC and PS-pC (Figure 8b). After air activation, sample APS-pC exhibited a $5.1 \mathrm{~mA} \mathrm{~cm}^{-2}$ in oxygen reduction current density at a rotation rate of $1600 \mathrm{rad}$, while PS-pC only performed a value of $3.5 \mathrm{~mA}$ $\mathrm{cm}^{-2}$. The current density of sample APS-pC exhibited a more close value to that of commercial 20\% Pt/C when compared to that of sample PS-pC. The Koutecky-Levich plot of sample APS-pC indicated a nearly 4-electron pathway (Figure 8c), showing a significant improvement on efficiency of reduction efficiency. With comparison of PS-pC, the half-wave potential of APS-pC was negatively shifted. This further supports that the binary doping improves catalytic activity while enlarged pore size benefits the oxygen diffusion.

Table 4 Nitrogen sorption data and compositional data of sample APS-pC.

\begin{tabular}{ccccccccc}
\hline $\begin{array}{c}\text { Sample } \\
\text { ID }\end{array}$ & $\begin{array}{c}\mathrm{S} \\
(\mathrm{at} \%)\end{array}$ & $\mathrm{P}$ & $\begin{array}{c}\mathrm{S}_{\text {BET }} \\
\mathrm{m}^{2} \mathrm{~g}^{-1}\end{array}$ & $\mathrm{~S}_{\text {meso }}$ & $\mathrm{S}_{\text {micro }}$ & $\begin{array}{c}\mathrm{V}_{\text {meso }} \\
\mathrm{cm}^{3} \mathrm{~g}^{-1}\end{array}$ & $\mathrm{~V}_{\text {micro }}$ & $\begin{array}{c}\mathrm{D}_{\text {meso }} \\
\mathrm{nm}\end{array}$ \\
\hline APS-pC & 0.3 & 0.8 & 953.2 & 289.8 & 677.5 & 0.62 & 0.09 & 6.0 \\
\hline
\end{tabular}

\section{Conclusion}

$\mathrm{P}$ and $\mathrm{S}$ were introduced by phosphorus pentasulfide into porous carbon by sol-gel processing. The $\mathrm{P} / \mathrm{S}$ co-doping resulted in porous carbon with high mesopore surface area and enlarged pore size both in micropore and mesopore regions. Sulfur 
dominated the improvement of the degree of graphitization of porous carbon by the removal of amorphous carbon through the formation of S-carbon containing gases $\left(\mathrm{CS}_{2}\right)$. The specific capacitance of the single electrode of P/S co-doped porous carbon increased $43.5 \%$ than that of pristine porous carbon. P contributed complementary pseudocapacitance in organic electrolyte while $\mathrm{S}$ content was lower than the limit sensitivity of detectable pseudocapcitance. In addition, enlarged mesopore size and mesopore surface area are beneficial for $\mathrm{O}_{2}$ diffusion, caused increased oxygen reduction current density. Co-doping strategy of $\mathrm{P}$ and $\mathrm{S}$ positively shifted the onset potential and presented a superb resistance to the crossover effects for oxygen reduction reaction in alkaline media. With further air activation, the specific capacitance of single electrode of sample PS-pC increased from $21.1 \mathrm{~F} \mathrm{~g}^{-1}$ to $103.5 \mathrm{~F}$ $\mathrm{g}^{-1}$, indicating an excellent energy storage capability. In addition, the activated sample APS-pC exhibited a negative shifted half-wave potential compared to sample PS-pC, which is due to the removal of $\mathrm{P}$ and $\mathrm{S}$ during activation. The oxygen reduction current density of sample APS-pC performed a more close value to that of commercial $20 \% \mathrm{Pt} / \mathrm{C}$.

\section{Acknowledgement}

This work has been supported by the One Hundred Talent Plan of Chinese Academy of Sciences, National Natural Science Foundation of China (21307145), the National Science Foundation (NSF, DMR-1505902), Key Project for Young Researcher of State Key Laboratory of High Performance Ceramics and Superfine Microstructure, the Youth Science and Technology Talents "Sail" Program of Shanghai Municipal 
Science and Technology Commission (No. 15YF1413800) and the research grant (No. 14DZ2261203) from Shanghai government.

\section{Reference}

[1] R. A. Costa, J. R. Camacho, J. Power Source, 2006, 161, 1176.

[2] J. A. Andujar, F. Segura, Renew. Sustain. Energy Rev., 2009, 13, 2309.

[3] S. Candelaria, R. Chen, Y. Jeong, G. Cao, Energy Environ. Sci., 2012, 5, 5619.

[4] D. Hulicova, J. Yamashita, Y. Soneda, H. Hatori, M. Kodama, Chem. Mater., 2005, $17,1241$.

[5] C. Ania, V. Khomenko, E. Raymundo-Pinero, J. Parra, F. Beguin, Adv. Funct. Mater., 2007, 17, 1828.

[6] F. Beguin, K. Szostak, G. Lota, E. Frackowiak, Adv. Mater., 2005, 17, 2380.

[7] W. Yang, T. Fellinger, M. Antonietti, J. Am. Chem. Soc., 2011, 133, 206.

[8] C. Rao, C. Cabrera, Y. Ishikawa, J. Phys. Chem. Lett., 2010, 1, 2622.

[9] Y. Wang, Y. Shao, D. Matson, J. Li, Y. Lin, ACS Nano, 2010, 4, 1790.

[10] J. Wei, D. Zhou, Z. Sun, Y. Deng, Y. Xia, D. Zhao, Adv. Funct. Mater., 2013, 23, 2322;

[11] L. Li, E. Liu, J. Li, Y. Yang, H. Shen, Z. Huang, X. Xiang, W. Li, J. Power Sources, 2010, 195, 1516.

[12] W. Kicinski, M. Szala, M. Bystrzejewski, Carbon, 2014, 68, 1.

[13] Y. Huang, S. Candelaria, Y. Li, Z. Li, J. Tian, L. Zhang, G. Cao, J. Power Sources, 2014, 252, 90.

[14] Y. Zhou, S. Candelaria, Q. Liu, Y. Huang, E. Uchaker, G. Cao, J. Mater. Chem. A, $2014,2,8742$. 
[15] Y. Zhou, S. Candelaria, Q. Liu, E. Uchaker, G. Cao, Nano Energy, 2015, 12, 567.

[16] D. Zhang, Y. Hao, L. Zheng, Y. Ma, H. Feng, H. Luo, J. Mater. Chem. A, 2013, 1, 7584.

[17] T. Wang, L. Wang, D. Wu, W. Xia, D. Jia, Sci. Rep., 2015, 5, 9591.

[18] X. Chen, X. Chen, X. Xu, Z. Yang, Z. Liu, L. Zhang, X. Xu, Y. Chen, S. Huang, Nanoscale, 2014, 6, 13740.

[19] W. Li, D. Yang, H. Chen, Y. Gao, H. Li, Electrochimica Acta, 2015, 165, 191.

[20] L. Zhang, J. Niu, M. Li, Z. Xia, J. Phys. Chem. C, 2014, 118, 3545.

[21] Z. Yang, Z. Yao, G. Fang, G. Li, H. Nie, X. Zhou, X. Chen, S. Huang, ACS Nano, 2012, 6, 205.

[22] J. Liang, Y. Jiao, M. Jaroniec, S. Qiao, Angew. Chem., 2012, 124, 11664.

[23] J. Xu, G. Dong, C. Jin, M. Huang, L. Guan, ChemSusChem, 2013, 6, 493.

[24] Y. Li, H. Zhang, Y. Wang, P. Liu, H. Yang, X. Yao, D. Wang, Z. Tang, H. Zhao, Energy Environ. Sci., 2014, 7, 3720.

[25] J. You, M. Ahmed, H. Han, J. Choe, Z. Ustundag, S. Jeon, J. Power Sources, $2015,275,73$.

[26] X. Wang, X. Li, L. Zhang, Y. Yoon, P. Weber, H. Wang, J. Guo, H. Dai, Science, 2009, 324, 768.

[27] Y. Tan, J. Lee, J. Mater. Chem. A, 2013, 1, 14814.

[28] B. Quan, S. Yu, D. Chung, A. Jin, J. Park, Y. Sung, Y. Piao, Sci. Rep., 2014, 4, 5639.

[29] S. Wang, E. lyyamperumal, A. Roy, Y. Xue, D. Yu, L. Dai, Angew. Chem., Int. 
Ed., 2011, 50, 11756.

[30] J. Zhu, P. Shen, RSC Adv., 2013, 3, 14686.

[31] Z. Liu, F. Peng, H. Wang, H. Yu, W. Zheng, J. Yang, Angew. Chem., 2011, 123, 3315.

[32] D. Hulicova-Juracakova, A. Puziy, O. Poddubnaya, F. Suarez-Garcia, J. Tascon, G. Lu, J. Am. Chem. Soc., 2009, 131, 5026.

[33] J. Wu, Z. R. Yang, X. W. Li, Q. J. Sun, C. Jin, P. Strasser, R. Z. Yang, J. Mater. Chem. A, 2013, 1, 9889.

[34] J. McBain, J. Am. Chem. Soc., 1935, 57, 699.

[35] C. Marino, P. Nascente, S. Biaggio, R. Rocha-Filho, N. Bocchi, Thin Solid Films, 2004, 468, 109.

[36] S. Glenis, A. Nelson, M. Labes, J. Appl. Phys., 1999, 86, 4464.

[37] H. Becerril, J. Mao, Z. Liu, R. Stoltenberg, Z. Bao, Y. Chen, ACS Nano, 2008, 2, 463.

[38] K. Sing, D. Everett, R. Haul, L. Moscou, R. Pierotti, J. Rouquerol, T. Siemieniewska, Pure Appl. Chem., 1985, 57, 603.

[39] J. Vallerot, X. Bourrat, A. Mouchon, G. Chollon, Carbon, 2006, 44, 1833.

[40] W. Bacsa, J. Lannin, D. Pappas, J. Cuomo, Phys. Rev. B, 1993, 47, 10931.

[41] N. McEvoy, N. Peltekis, S. Kumar, E. Rezvani, H. Nolan, G. Keele, Carbon, 2012, 50, 1216.

[42] T. Jawhari, A. Roid, J. Casado, Carbon, 1995, 33, 1561.

[43] S. Candelaria, B. Garcia, D. Liu, G. Cao, J. Mater. Chem., 2012, 22, 9884. 
[44] A. Feaver, G. Cao, Carbon, 2006, 44, 590.

[45] S. Meher, G. Rao, J. Power Sources, 2012, 215, 317.

[46] S. L. Candelaria, B. B. Garcia, D. W. Liu, G. Z. Cao, J. Mater. Chem. A, 2012, 22 , 9884.

[47] Y. Zhou, S. L. Candelaria, Q. Liu, E. Uchaker, G. Z. Cao, Nano Energy, 2015, 12, 567.

[48] H. Du, L. Gan, B. Li, P. Wu, Y. Qiu, F. Kang, R. Fu, Y. Zeng, J. Phys. Chem. C, 2007, 111, 2040.

[49] H. Wang, Y. Liang, Y. Li, H. Dai, Angew. Che., Int. Ed., 2011, 50, 10969.

[50] L. Zhang, Z. Su, F. Jiang, L. Yang, J. Qian, Y. Zhou, W. Li, M. Hong, Nanoscale, $2014,6,6590$.

[51] K. P. Gong, F. Du, Z. H. Xia, M. Durstock, L. M. Dai, Science, 2009, 323, 760. 


\section{Figure Captions:}

Figure 1 The high resolution XPS spectra of (a) C1s, (b) P2p and (c) S2p for the sample PS-pC.

Figure 2 (a) S- and (b) P-containing gases MS patterns of $p C / \mathrm{P}_{2} \mathrm{~S}_{5}$ mixture after undergoing heat-treatment. This heat-treatment was implemented in nitrogen with a $5{ }^{\circ} \mathrm{C} \min ^{-1}$ ramping rate from room temperature to $1000{ }^{\circ} \mathrm{C}$. The $\mathrm{pC} / \mathrm{P}_{2} \mathrm{~S}_{5}$ mixture after this heat-treatment represents the sample PS-pC.

Figure 3 (a) Nitrogen sorption isotherms, (b) mesopore size distribution and (c) micropore size distribution in samples $\mathrm{pC}$ and $\mathrm{PS}-\mathrm{pC}$ calculated from nitrogen sorption isotherms using the BJH and DA models.

Figure 4 Deconvoluted Raman spectra of (a) PS-pC and (b) pC showing D, G, I an D" bands with values of $I(D) /(G)$. The sample with the introduction of $P$ - and S-heteroatoms shows lower $\mathrm{I}(\mathrm{D}) / \mathrm{I}(\mathrm{G})$ value as compared to the non-doped sample $\mathrm{pC}$, indicating an improved degree of graphitization.

Figure 5 (a) CV and (b) GC curves of sample pC and PS-pC. GC curves were taken at a current of $0.5 \mathrm{~mA}$ and $\mathrm{CV}$ curves were measured at the voltage window from 0 to 2.0 V. The dropped IR after P/S doping was illustrated in inset of (b). 
Figure 6 (a) the cycling stability performance of sample PS-pC and pC tested under $0.5 \mathrm{~mA}$ current (b) Nyquist plots at high and low frequencies of sample PS-pC and pC in set. Sample PS-pC showed the higher capacitance with a smaller charge transfer resistance compared with sample pC (c) GCs of sample APS-pC with air activation at $0.5 \mathrm{~mA}$ current.

Figure 7 (a) CV curves of sample PS-pC and pC on glassy carbon electrodes in $\mathrm{O}_{2}$-saturated (solid line) or $\mathrm{N}_{2}$-saturated (dash line) in $0.1 \mathrm{M} \mathrm{KOH}$. (b) Rotating-disk voltammograms of sample PS-pC and $\mathrm{pC}$ in saturated $0.1 \mathrm{M} \mathrm{KOH}$ with a sweep rate of $10 \mathrm{mV} \mathrm{s}^{-1}$ at the $1600 \mathrm{rad}$. Inset shows the zoom out figure between $-0.4 \mathrm{~V}$ to $1.0 \mathrm{~V}$. Rotating-disk voltammograms of $\mathrm{pC}(\mathrm{c})$ and PS-pC (d) in $\mathrm{O}_{2}$-saturated $0.1 \mathrm{M} \mathrm{KOH}$ at the different rotation rates indicated. The insets in (c) and (d) show corresponding Koutecky-Levich plots $\left(\mathrm{J}^{-1}\right.$ versus $\left.\omega^{-1 / 2}\right)$ at different potentials.

Figure 8 (a) Chronoamperometric responses of sample PS-pC and Pt/C at $-0.25 \mathrm{~V}$ vs SCE in $\mathrm{O}_{2}$-saturated $0.1 \mathrm{M} \mathrm{KOH}$ followed by addition of methanol. (b) LSV curves of sample APS-pC, PS-pC and commercial 20\% Pt/C with sweep rate of $1600 \mathrm{rmp}$. (c) Rotating-disk voltammograms of sample APS-pC in $\mathrm{O}_{2}$-saturated $0.1 \mathrm{M} \mathrm{KOH}$ at the different rotation rates. The insets in (c) shows corresponding Koutecky-Levich plots $\left(\mathrm{J}^{-1}\right.$ versus $\left.\omega^{-1 / 2}\right)$ at different potentials.

Table 1 XPS composition data for samples PS-pC and pC. 
Table 2 Nitrogen sorption data for samples PS-pC and pC.

Table 3 Specific capacitance of the single electrode of sample pC and PS-pC.

Table 4 Nitrogen sorption data and compositional data of sample APS-pC. 


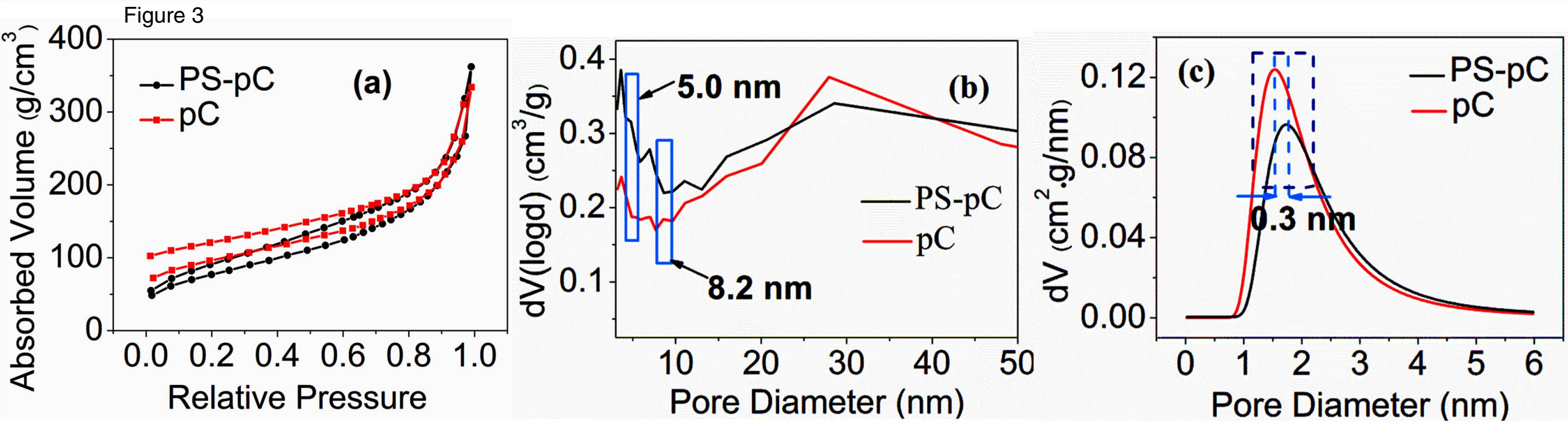




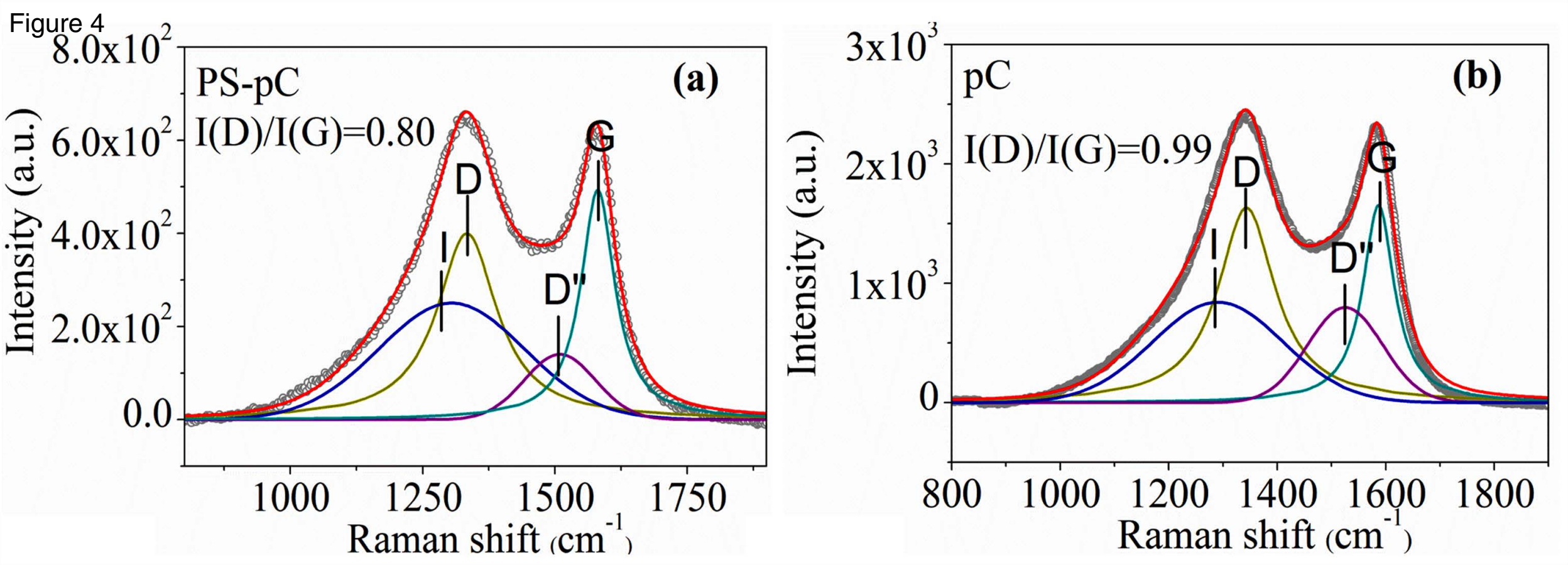


Figure 5

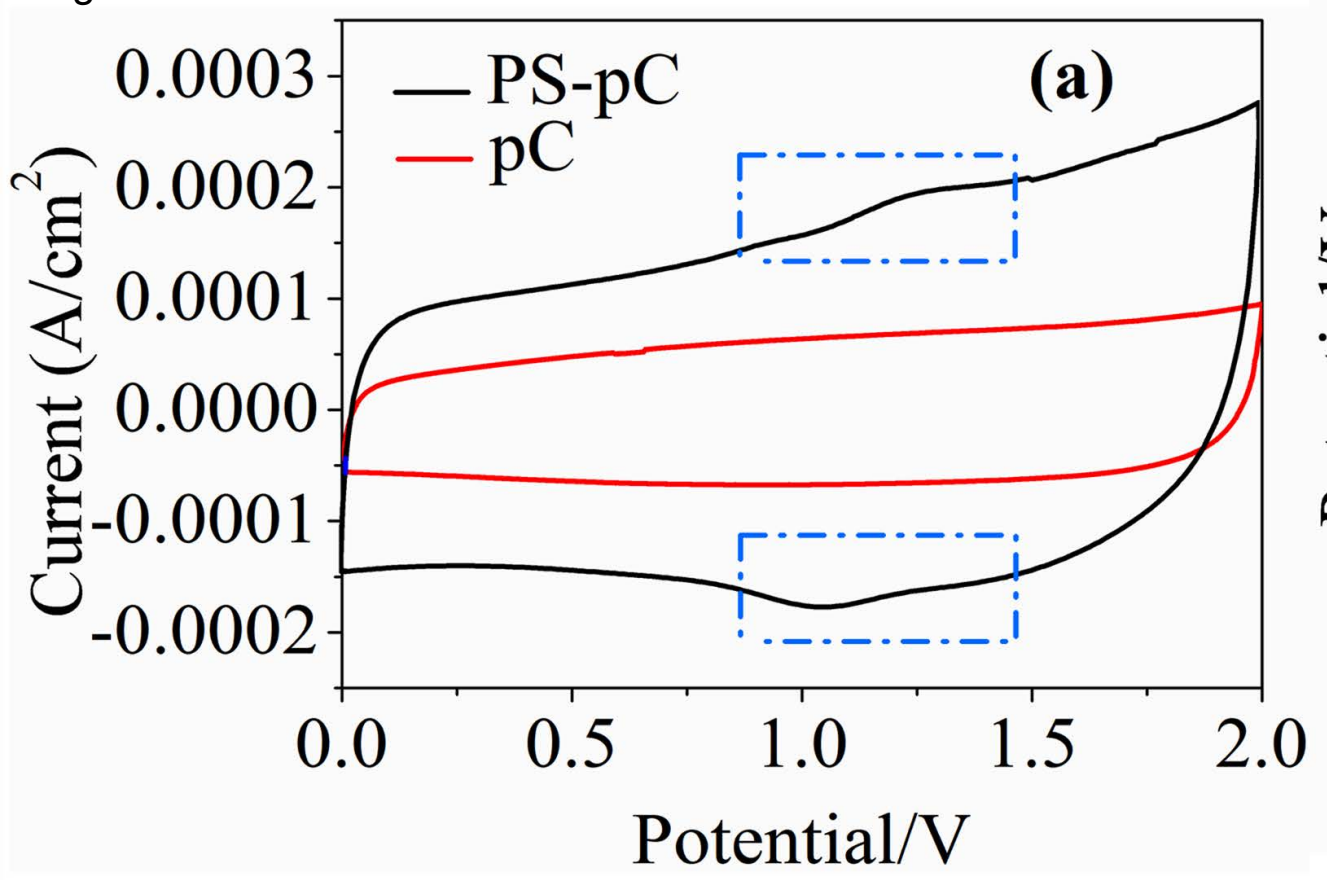

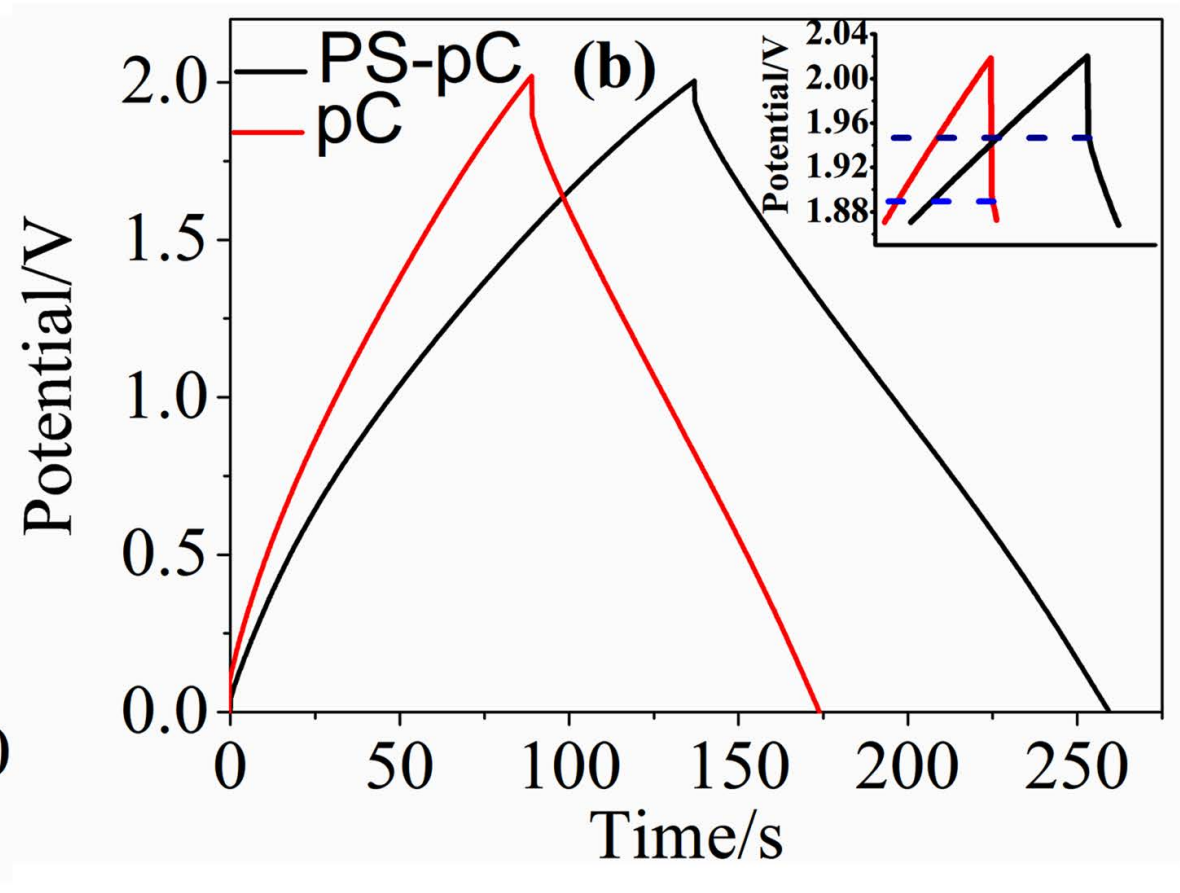


Figure 6
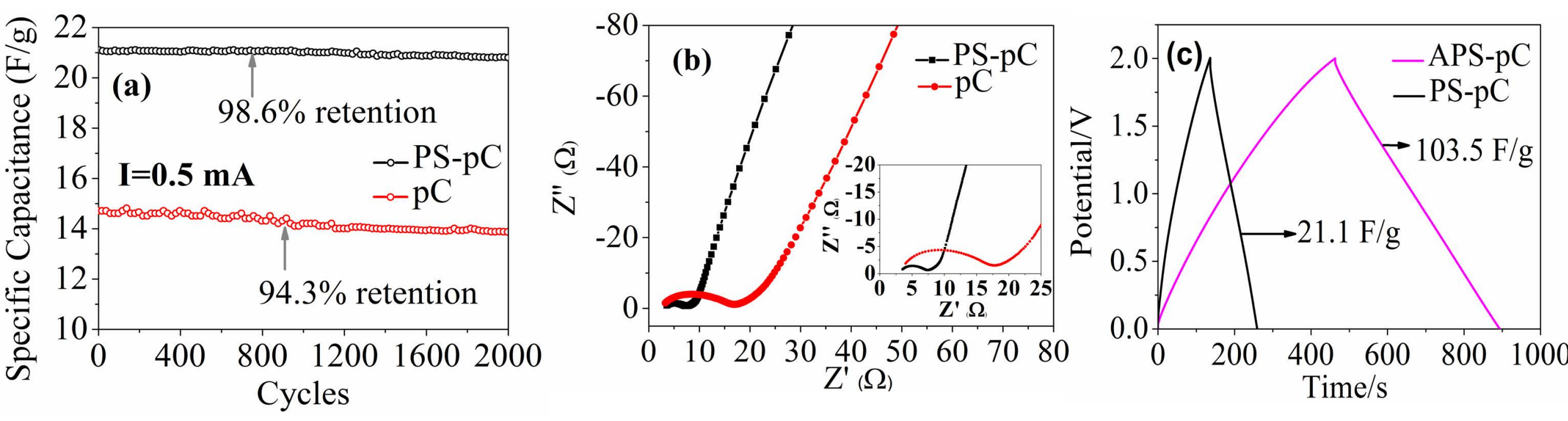


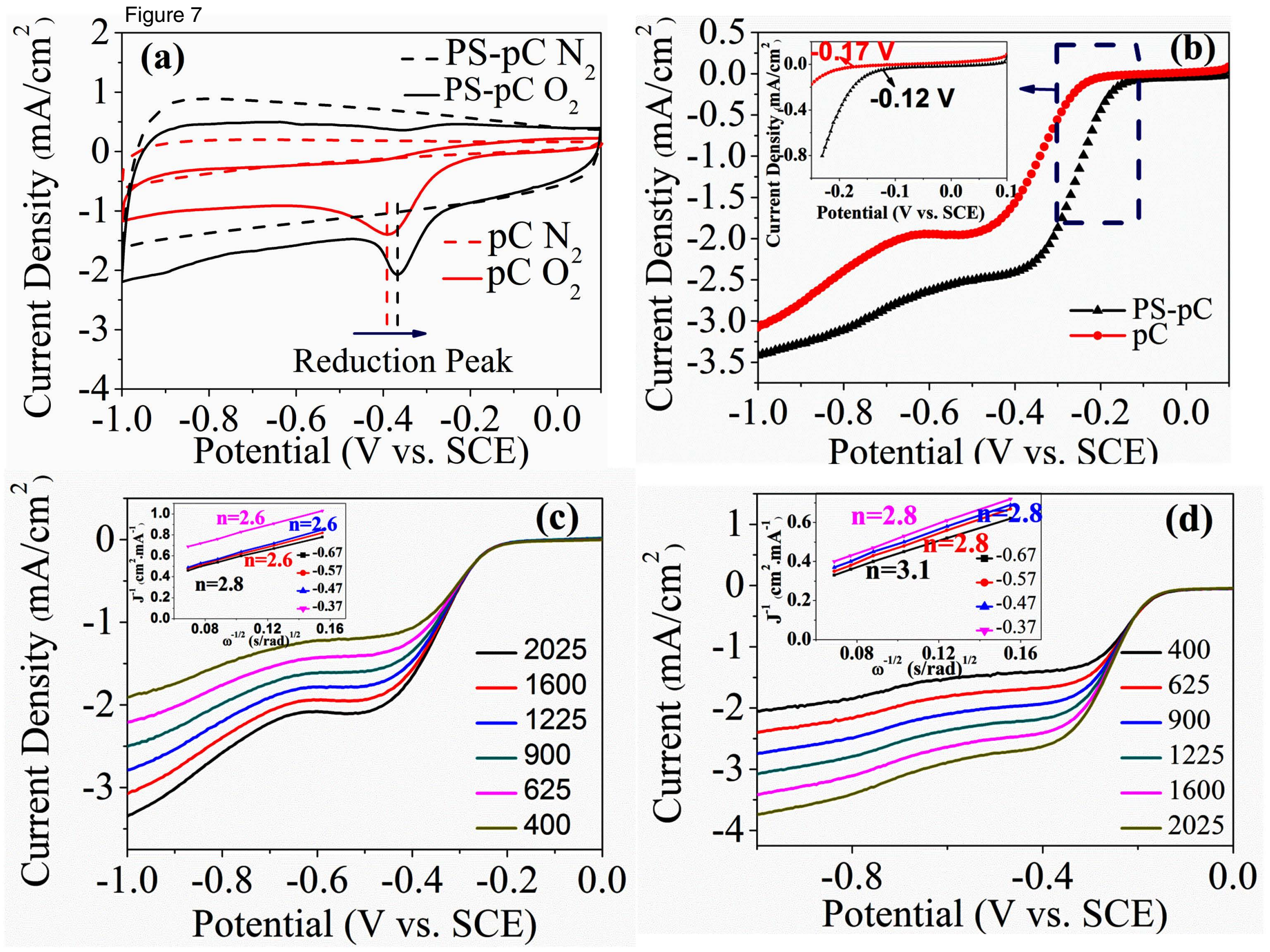



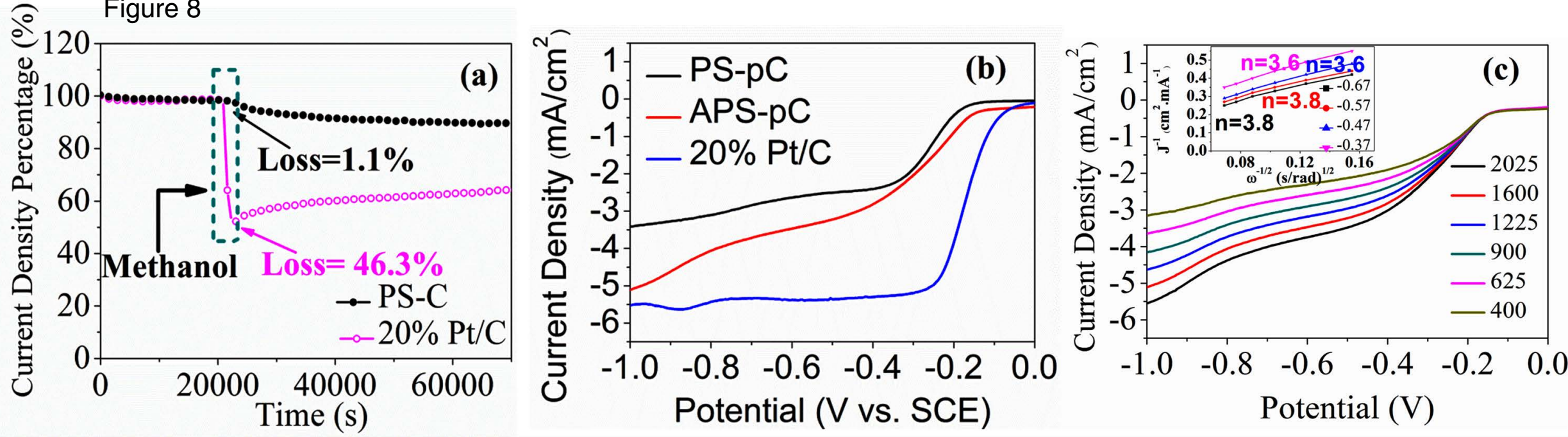